\title{
Previous reconstruction of severely atrophic maxilla with calvarial bone graft and implant supported fixed partial prosthesis - Case report
}

\author{
Magno Filho $L C^{1}$, Amato $M^{2}$, \\ Medeiros $R^{2}$, Naves $F^{2}$, \\ Al-Juboori $\mathrm{MJ}^{3}$, Pedron IG ${ }^{4}$ \\ Affiliations: \\ 1. Department of Implantology Funorte, \\ Mogi das Cruzes São Paulo, Brazil. \\ 2. Private practice. São Paulo, Brazil \\ 3. Lecturer of Periodontology Department, \\ Al-Rafidain College, Baghdad, Iraq. \\ 4. Professor of Department of \\ Periodontology and Implantology, \\ Faculty of Dentistry, Universidade Brasil, \\ São Paulo, Brazil.

\section{Corresponding author:} \\ Luiz Carlos Magno Filho \\ caimplantes@gmail.com
}

\begin{abstract}
Purpose: Autogenous bone graft is still considered the "gold standard" for bone augmentation of the jaws prior to dental implants placement. In cases of major bone defects, we can relinquish reconstructive techniques using grafts from extra buccal donor areas, such as the calvarial bone graft. Although this technique is well established in the literature, many professionals feel insecure in indicating this type of treatment to their patients, due to the high degree of complexity for the execution of the procedure and not acceptance by the patient.

Case report: A female patient, 42-year-old, had undergone reconstructive surgery by means of a calvarial bone graft for pre-maxilla reconstruction prior to dental implants placement in regions of 14 to 24 . The graft collection procedure was performed in a hospital setting and under general anesthesia. The grafts were transplanted from the calvarial bone to reconstruct the anterior maxilla. After 7 months, 4 dental implants were placed, allowing a future prosthetic rehabilitation. After the period of osseointegration, screw-retained partial fixed prosthesis was made, returning function and aesthetics to the patient.

Conclusion: In view of the clinical case and literature presented, it is concluded that patients with severe maxillary bone atrophy can undergo a successful reconstruction process with calvarial bone grafts and dental implants.
\end{abstract}

\section{KEYWORDS}

Jaw, edentulous, bone transplantation, calvaria, dental implants 


\section{INTRODUCTION}

In the last decades, there has been an increase in the number of cases of patients undergoing dental implant surgery. This modality of treatment has shown foreseeable results both for partial rehabilitations as well as for total rehabilitations. 1,2,3,10,13,15,21 However, in cases where there is intense alveolar bone resorption, implant placement in a favorable prosthetic position becomes difficult or often impractical. $4,5,6,7$ In order to try to avoid such situations, several reconstructive techniques aiming at bone volume increase have been proposed. The main techniques described in the literature are guided bone regeneration (GBR), onlay grafts (associated or not to several of biomaterials types), osteogenic distraction (OD), bone expansion with corticotomy and use of platelet-rich fibrin (PRF). 1,2,4,10,21,22

Among the aforementioned techniques, the use of autogenous bone block grafts still represents an important grafting modality in rehabilitations involving dental implants. It is a versatile technique, well documented in the literature and allows the correction of several types of bone defects in different clinical situations. In addition, it is a modality that aggregates the three desired graft properties: osteoinduction, osteoconduction and osteogenesis. ${ }^{1,2,5,6,7}$

The present case report shows the use of this important modality of grafting as an alternative for pre-maxilla reconstruction prior to the dental implant's placement.

\section{CASE REPORT}

A 42-year-old, female patient, presents to the office with aesthetic complaints in pre-maxilla region, discomfort and dissatisfaction with the use of a removable partial denture. In the anamnesis, underlying diseases, harmful habits or even use of medications

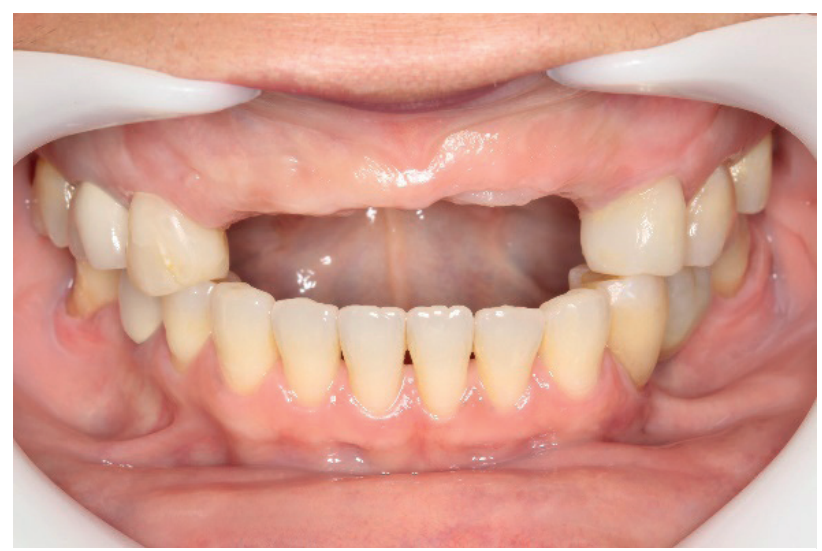

Figure 1. Frontal view and missing teeth 14, 13, 12, 11, 21, 22, 23, 24 in a chronic manner was not found. At the clinical examination, we observed a partially edentulous maxilla, with absence of 14 to 24 and presence of residual border with advanced bone resorption, mainly in the anteroposterior direction (Figure 1). In the computed tomography examination, there was severe atrophy of the anterior extension of the residual bone border of the maxilla, with evident bone loss in height and thickness (Figure 2). ${ }^{23}$

With all the data, the treatment plan was proposed based on the clinical evaluation, as well as, the imaging exams. Initially, a previous reconstruction of the maxilla was planned with an onlay graft and, subsequently, the dental implants placement for the future manufacture of a screw-retained partial fixed prosthesis.

The patient was guided in relation to the grafting modalities existing in the literature for the solution of her case, as well as, the advantages and disadvantages of each one of the techniques. In the present case, one factor was decisive for the selection of the calvarial bone as the donor area: the need for fully reconstruction of the pre-maxilla.

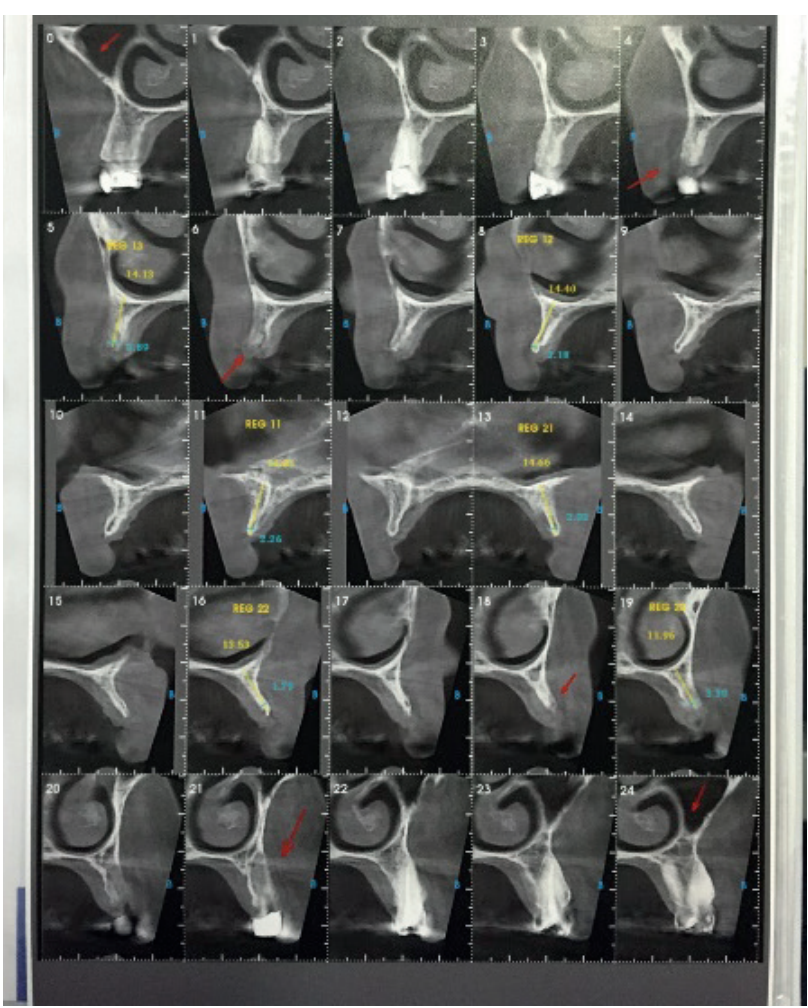

Figure 2. Computed tomography of maxilla show the advanced bone resorption 


\section{Reconstructive phase}

\section{Donor site}

During the reconstructive procedure, the removal of the autogenous graft from the calvarial bone was performed, under general anesthesia, with naso-tracheal intubation. A parasagittal incision located in the right parietal region was made as a surgical access to the chosen donor bed (Figure 3). After the tissue detachment and exposure of the region of interest, the sagittal suture was located, and $1.5 \mathrm{~cm}$ was respected to avoid contact with the superior sagittal sinus. Osteotomies were performed using ultrasonic tips and thin-tipped laminated drills and, after the delimitation of the regions for graft removal, delicate chisels were used gently to aid in the detachment of monocortical bone graft - 40x60 mm (Figure 4). After complete removal, the graft were packed in $0.9 \%$ saline solution and a titanium mesh (KLS Martin Group, Germany) was accommodated on the defect, which was filled with a hidroxiapatite paste (SINTLIFE', Finceramica, Italy) in order to promote better tissue neoformation in the region, reducing the risk of palpable defects in the donor area (Figure 5). Control of hemostasis, surgical revision and suture by planes were performed (Figure 6).

\section{Receiving site}

For surgical access to the bone defect, an incision was made at the ridge crest, slightly facing the palatine, followed by two vertical incisions. A full-thickness flap was performed, and the recipient bed was prepared through perforations, with low speed handpiece and abundant saline solution, in the outer cortical to promote greater blood perfusion at the site (Figure 7). The graft, which had previously been remodeled, by low speed handpiece and thin drill, to be passively adapted to the maxillary bone remnant, was fixed rigidly (Figure 8) using screws of $1.5 \mathrm{~mm}$

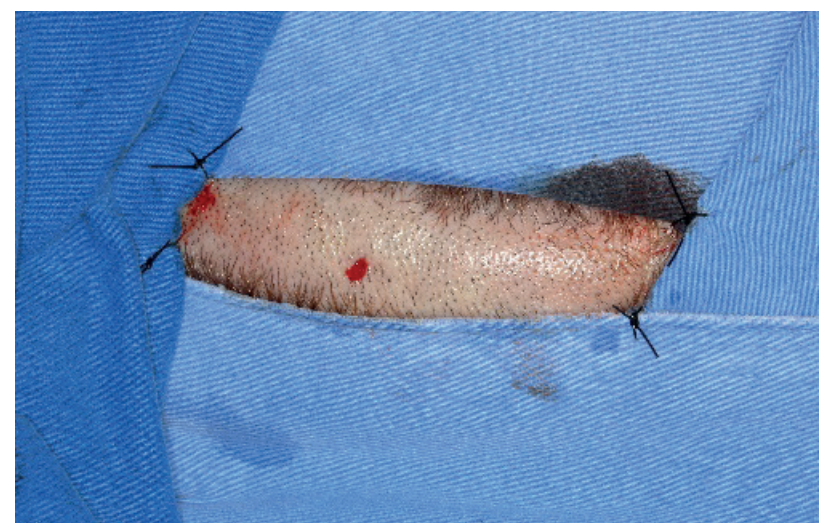

Figure 3. Donor site access - right parietal region

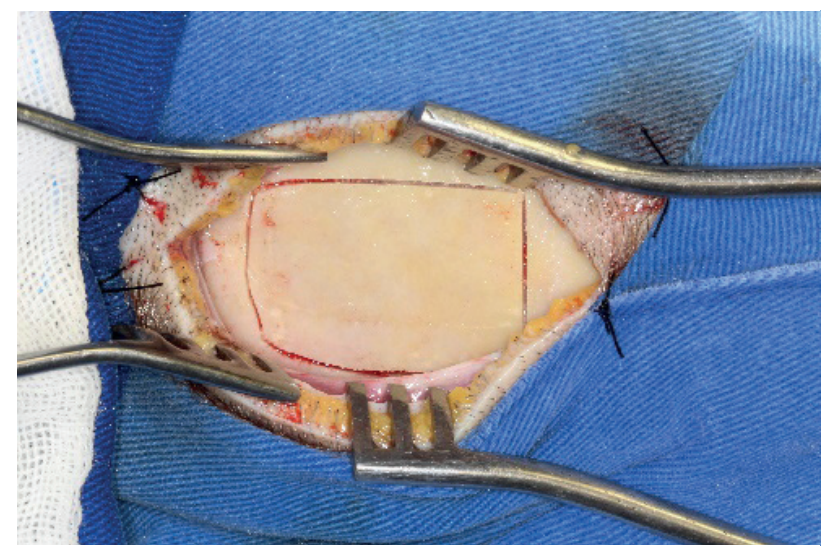

Figure 4. Calvarial bone exposed - 40x60 mm

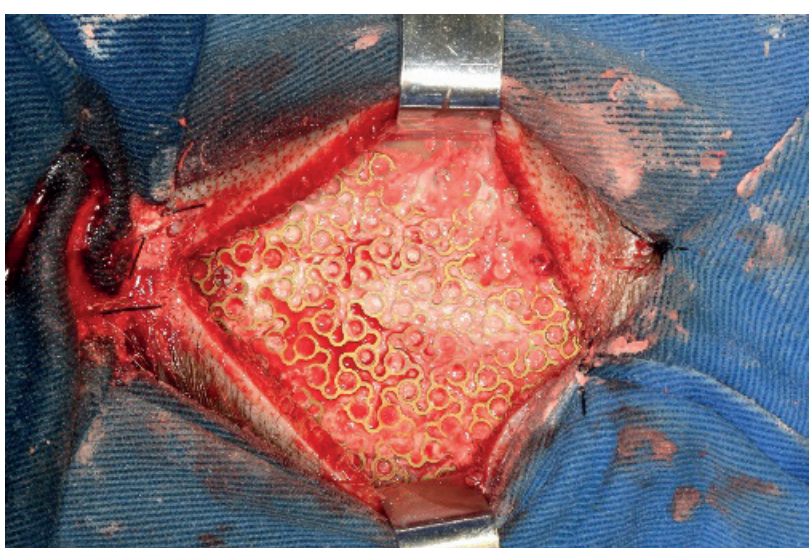

Figure $\mathbf{5}$. Donor site was filled by hydroxyapatite paste and protected by titanium mesh

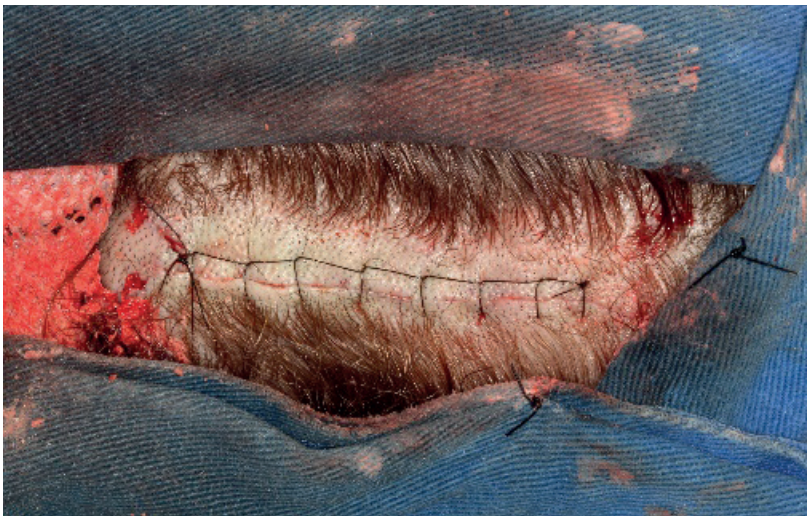

Figure 6. Donor site suture

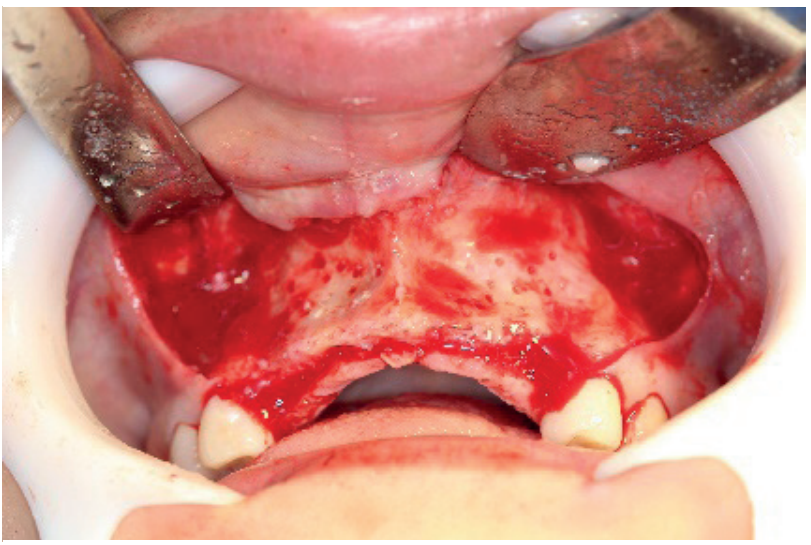

Figure 7. The native bone was scalped by low speed handpiece and abundance saline solution to increase the vascularization

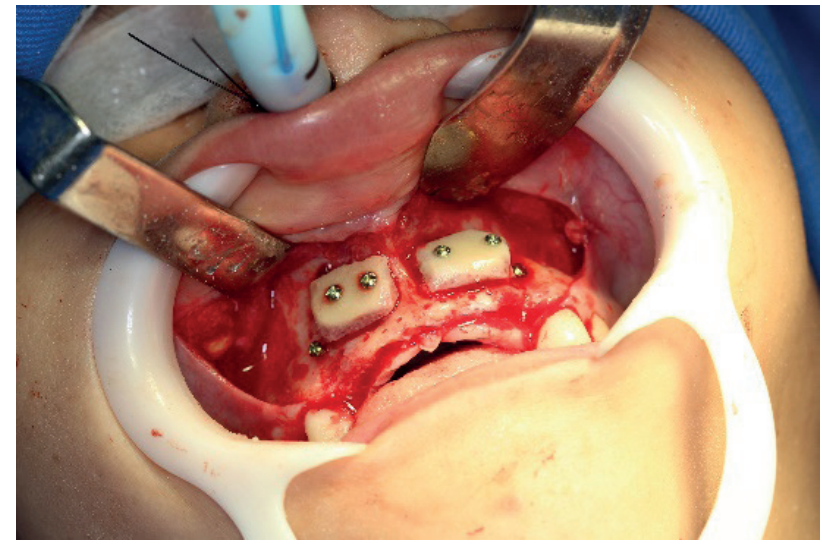

Figure 8. Onlay bone graft $(20 \times 20 \mathrm{~mm})$ fixed by screws screws of $1.5 \mathrm{~mm}$ diameter and $12 \mathrm{~mm}$ length 
diameter and $12 \mathrm{~mm}$ length (KLS Martin Group, Germany). All observed gaps were filled with bovine mineral bone (BioOss', Geistlich Biomaterials, Switzerland) and stabilized by collagen membranes (Bio-Guide", Geistlich Biomaterials, Switzerland) (Figure 9), eliminating the knife blade regions, harmonizing the reconstructed region and reducing the risk of reabsorption of the autogenous graft. Hemostasis was reevaluated, followed by primary close of the wound (Figure 10).

The postoperative recommendations were clearly explained and Amoxicillin $875 \mathrm{mg}$ and Potassium Clavulanate $125 \mathrm{mg}$ were prescribed every 12 hours for ten days; Ketoprofen 100 mg every 12 hours for three days and Dipyrone Sodium $1 \mathrm{~g}$ every 6 hours in case of pain. In addition, mouthwashes with chlorhexidine solution $0.12 \%$ were prescribed twice daily for fifteen days, combined with rigorous oral hygiene.

The removable prosthesis used by the patient was relieved in all its extension, removing the vestibular flange, to be totally passive and without direct contact with the wound. The postoperative period was uneventful, and the sutures were removed after the 15th day of surgery.

\section{Rehabilitation phase}

After seven months postoperative of reconstructive surgery, a new computed tomography was requested to evaluate the grafted region. In the images it was possible to observe a significant increase of bone volume in the region, allowing the implants placement with favorable 3D prosthetic positioning (Figure 11).

Prior to implant placement, $1 \mathrm{~g}$ of Amoxicillin and $8 \mathrm{mg}$ of Dexamethasone were prescribed. Under local anesthesia, a mucoperiosteal flap with crestal incision was slightly turned towards the palate, followed by two vertical incisions in adjacent teeth (Figure 12).

After the raising of the mucoperiosteal flap, the graft fixation screws were removed and four implants were placed in the regions of 13,11, 21 and 23 (Cone Morse Taper, Singular Implants, Brazil), with a torque of approximately $30 \mathrm{~N}$. It was chosen to immediately place healing abutments to allow faster remodeling of the peri-implant tissues, eliminating a second surgical time to reopen the implants (one stage implants). Single sutures were performed, allowing primary closure of the surgical wound (Figure 13).

The patient was guided and medicated according to the following protocol: Amoxicillin 500 mg every 8 hours for 7 days; Ketoprofen $100 \mathrm{mg}$ every 12 hours for 5 days and Dipyrone Sodium $1 \mathrm{~g}$ every 6 hours in case of pain. In addition, $0.12 \%$ Chlorhexidine Gluconate mouthrinse was prescribed every 12

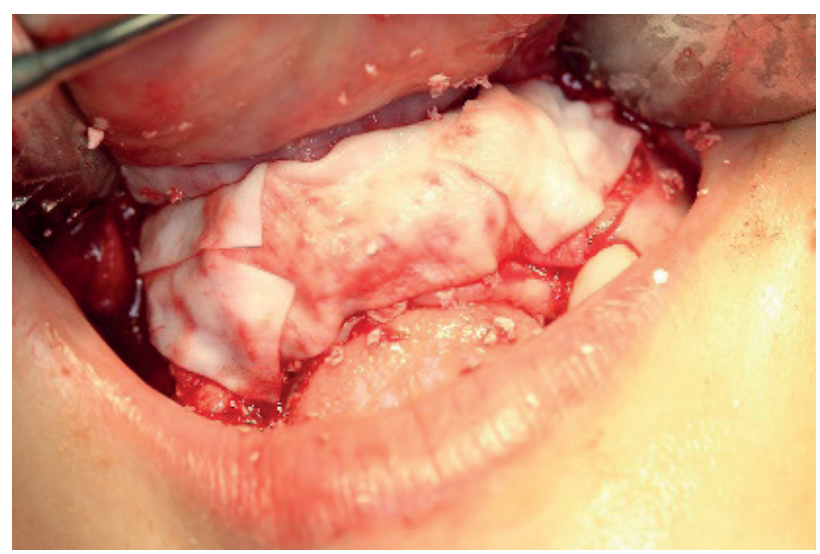

Figure 9. The gaps were filled by mineral bovine mineral bone and collagen membranes was gently placed

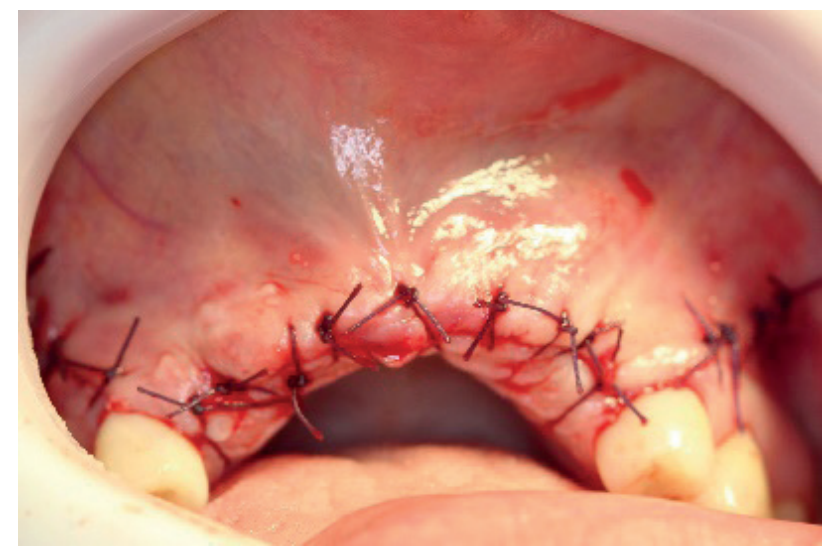

Figure 10. Primary closure of wound

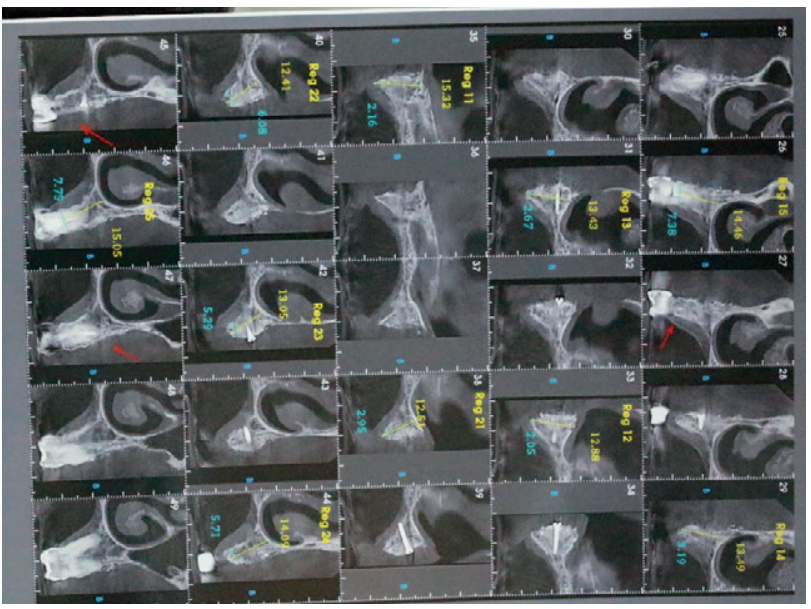

Figure 11. Computed tomography of maxilla after seven months of bone augmentation

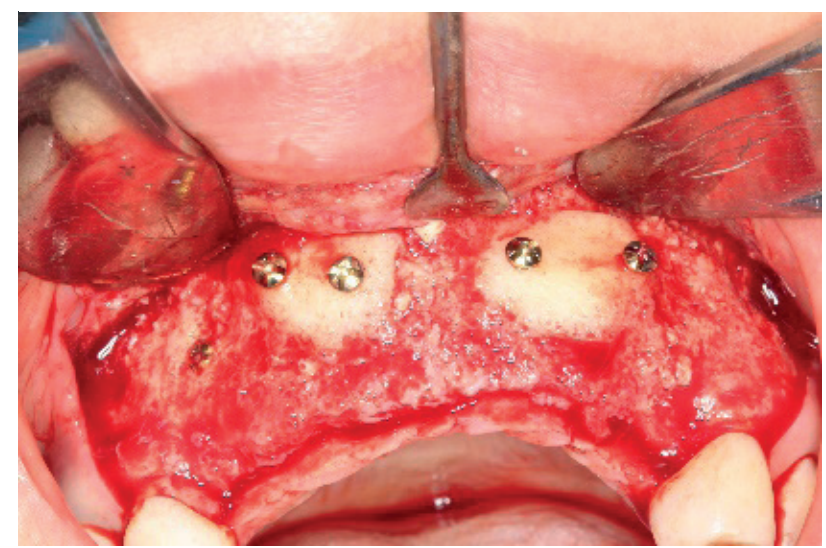

Figure 12. Access to the maxilla before implant placement

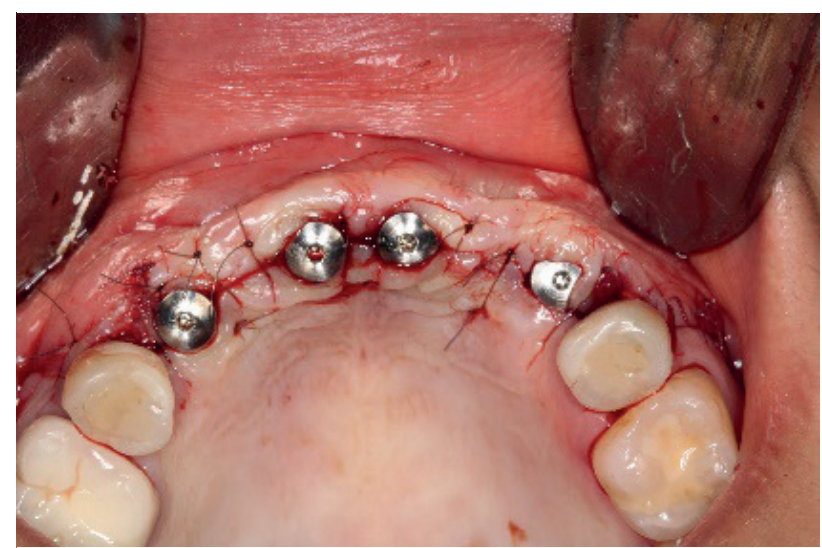

Figure 13. Dental implants placement in the correct 3D position and healing abutments placement. Note the good adaptation of healing caps and keratinized mucosa 
hours for 12 days. The postoperative period was uneventful, and the sutures were removed after 10 days.

Four months after the implant placement, the prosthetic rehabilitation process was started for the preparation of a screw-retained partial fixed prosthesis (Figure 14). All steps were followed according to the literature and, after the occlusal adjustment, the porcelain prosthesis was installed with final torque of $20 \mathrm{~N}$ (Figure 15).

\section{DISCUSSION}

The choice of the donor site depends fundamentally on some principles. First, the amount of bone needed must be compatible with the donor site. Secondly, it is necessary to consider the professional experience, risk / benefit evaluation of each of the techniques recommended, convenience with the patient's wishes, and finally, evaluation of the success and survival of the implants installed in grafted areas. ${ }^{2}$ In this way, the professional can decide more precisely the modality of grafting that will advocate for each case.

The donor site can be extra and intra-buccal. In cases involving large defects and requiring a greater amount of graft, removal of grafts from extra buccal sites, such as calvarium, iliac crest, rib and tibia, are recommended. ${ }^{24}$ We can still indicate the removal of the extra buccal graft in cases that involve access to multiple intraoral donor areas or that these areas are very close to the noble structures, such as the inferior alveolar nerve, the mental foramen and the dental roots; when the graft is removed, there may be no adequate margin of safety to withdraw the graft with the appropriate amount without causing permanent damage to the patient. ${ }^{9}$

Among the extrabuccal donor areas, the calvarial region has been shown to be a viable, predictable and safe option to be used as a donor site bed for grafting, prior to the dental implant's placement. $4,5,6$ This technique has many advantages over other extraoral techniques, such as low incidence of complications, low morbidity, high bone quality, a dense medulla with viable cells and a thick cortical layer, which decreases the rate of remodeling of the graft. $4,5,6,11,19$ The complications of this donor bed are considered low, epidural hematoma formation may occur (when the middle meningeal artery ruptures), exposure or laceration of the dura mater, and, more rarely, neurological complications. ${ }^{4,5,6,7,8,11,12,14,16,17,18,19}$

Much has been discussed regarding the acceptance (by professionals and patients) of this technique as a "gold standard" for maxillary reconstructions pre dental implants placement. In fact, because it is a procedure that requires a more complex surgical protocol, which requires an experienced and specialized team, and with risk of trans operative complications, it can generate some insecurity on the part of some professionals. However, studies have already shown that alveolar reconstructions by means of an autogenous graft of the calvarial is a safe, reproducible technique that is a good solution to allow a correct rehabilitation through dental implants in patients with bone atrophy of the jaw. ${ }^{7,9}$

Compared to other extraoral donor sites, such as the iliac crest, the studies revealed that the complaints were larger in the latter. Pain, discomfort and difficulty of ambulation were the most important signs and symptoms presented by the patients in the postoperative period, in comparison to the calvarial region. ${ }^{3,20,22}$ In addition, Carinci et al., 2005, in a longitudinal comparative study between bone grafts derived from iliac crest and calvarial, observed that after 10 months of the procedure, $83 \%$ of the calvarial graft remained in the recipient area against $61 \%$ of the
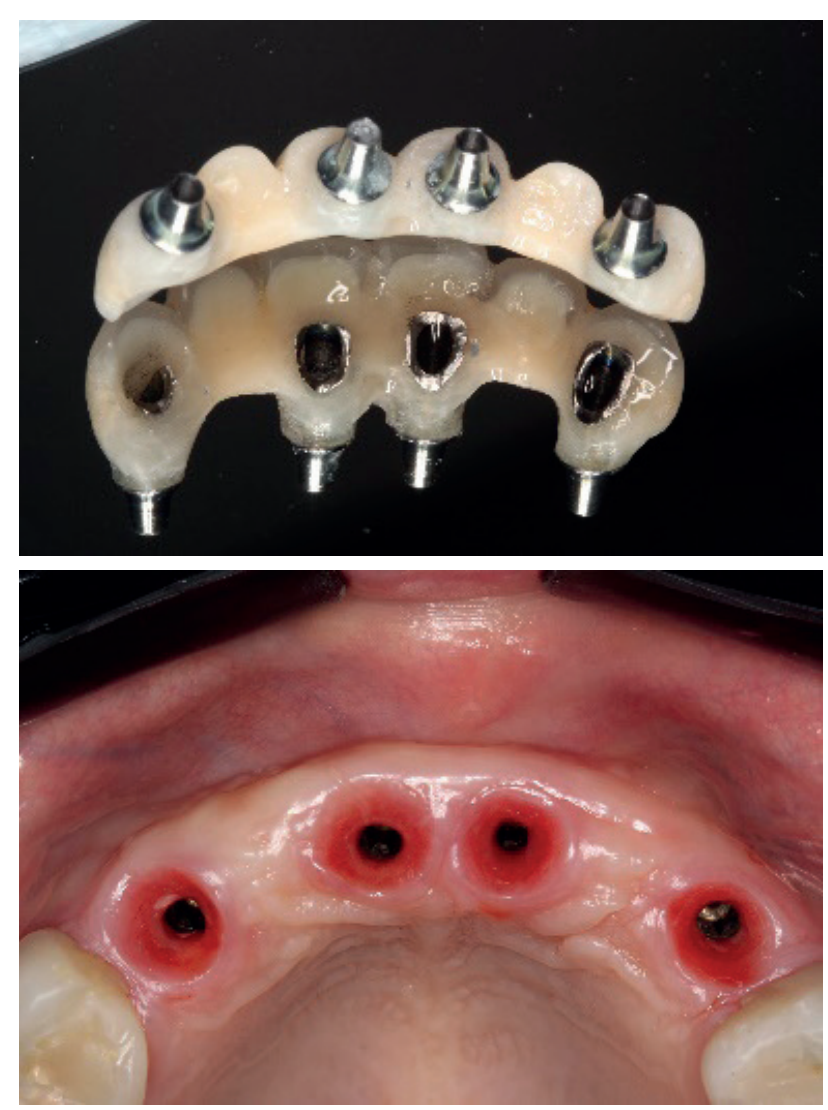

Figure 14. View of provisional prosthesis and gingival healing
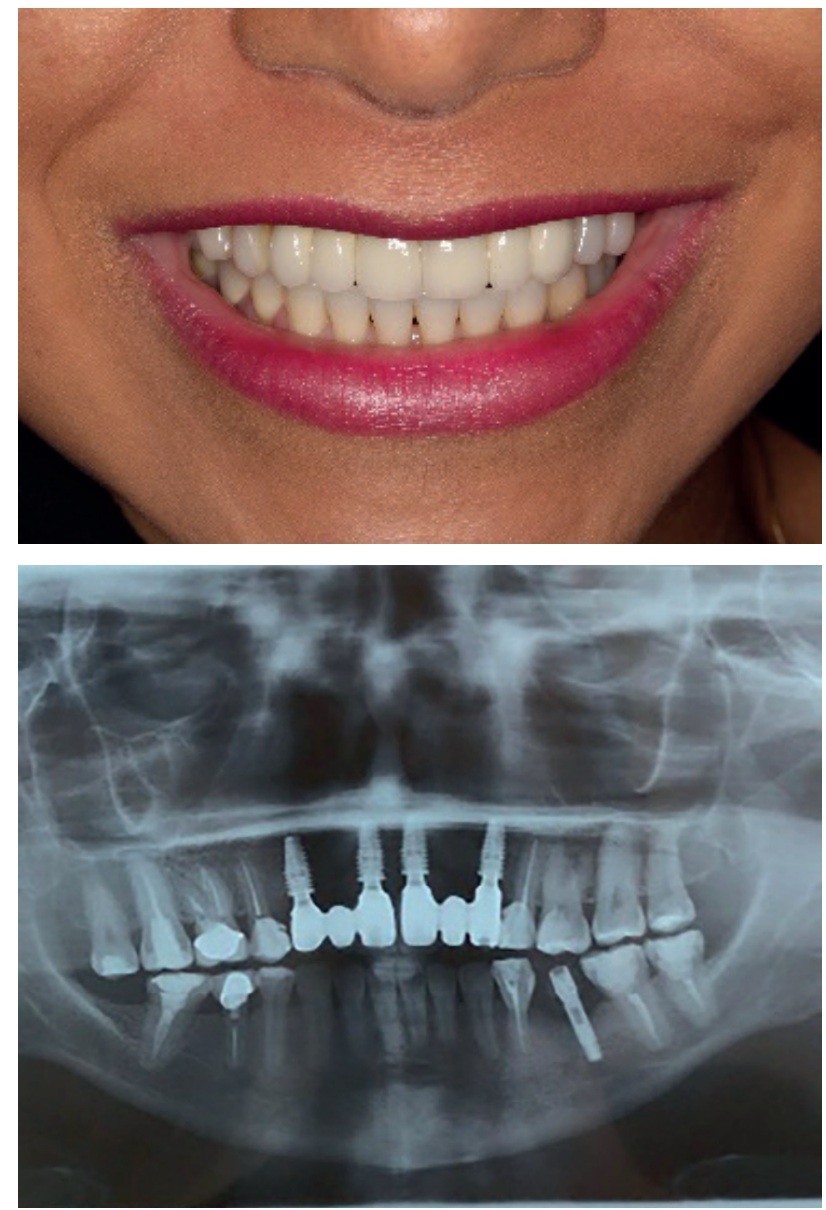

Figure 15. Fixed partial prosthesis placement and panoramic radiography after prosthesis placement 
graft derived from iliac crest

Mertens et al. (2017) also ensure that calvarial is a viable option for reconstruction of bone defects in the jaws prior to the implant placement. In their study, 17 patients with edentulous maxilla were submitted to reconstruction of bone defects with calvarial bone graft and implant placement. There were no complications related to the donor site and of the 107 implants placed, the survival rate obtained was 98.51\%. Quiles et al. (2015) also evaluated the survival rate of implants installed in areas reconstructed with calvarial bone graft. Of the 196 implants placement only 15 were lost (7.65\%). The mean bone loss was $1.76 \mathrm{~mm}$, ranging from $1.38 \mathrm{~mm}$ to $2.10 \mathrm{~mm}$ after 11 years of use. In contrast, Becktor et al. (2004) obtained a mean of bone loss in implants placement in grafted areas with $3.3 \mathrm{~mm}$ iliac crest bone after 6 years of follow-up.

\section{CONCLUSION}

In view of the clinical case and literature presented, it is concluded that patients with severe maxillary bone atrophy can undergo a successful reconstruction process with calvarial bone grafts and dental implants, demonstrating a stable clinical and radiographic situation in the long term.

\section{CONFLICT OF INTEREST STATEMENT(S), DISCLOSURE(S), AND/OR FINANCIAL SUPPORT INFORMATION}

The authors declare no conflict of interest. This study was selffunded by the authors.

\section{REFERENCES}

1. Aloy-Prósper A, Peñarrocha-Oltra D, Peñarrocha-Diago M, Peñarrocha-Diago M. Dental implants with versus without peri-implant bone defects treated with guided bone regeneration. J Clin Exp Dent. 2015 Jul 1;7(3):361-8.

2. Aghaloo TL, Misch C, Lin GH, lacono VJ, Wang HL. Bone Augmentation of the Edentulous Maxilla for Implant Placement: A Systematic Review. Int J Oral Maxillofac Implants. 2016;31:19-30.

3. Becktor JP, Isaksson S, Sennerby L. Survival analysis of endosseous implants in grafted and nongrafted edentulous maxillae. Int J Oral Maxillofac Implants. 2004 Jan-Feb;19(1):107-15.

4. Carinci F, Farina A, Zanetti U, Vinci R, Negrini S, Calura G, Laino G, Piattelli A.Alveolar ridge augmentation: a comparative longitudinal study between calvaria and iliac crest bone grafts. J Oral Implantol. 2005; 31(1):39-45.

5. Chiapasco M, Zaniboni M, Boisco M. Augmentation procedures for the rehabilitation of deficient edentulous ridges with oral implants. Clin Oral Implants Res. 2006 Oct;17 Suppl 2:136-59.

6. Chiapasco M, Gatti C, Gatti F. Immediate loading of dental implants placed in severely resorbed edentulous mandible reconstructed with autogenous calvaria grafts. Clin Oral Implants 2007 Feb;18(1):13-20.

7. Chiapasco M, Casentini P, Zaniboni M. Bone augmentation procedures in implant dentistry. Int J Oral Maxillofac Implants. 2009;24 Suppl:237-59.

8. Chiapasco M, Felisati G, Zaniboni M, Pipolo C, Borloni R, Lozza P. The treatment of sinusitis following maxillary sinus grafting with the association of functional endoscopic sinus surgery (FESS) and an intra-oral approach. Clin Oral Implants Res. 2013 Jun;24(6):623-9.

9. Chiapasco M, Tommasato G, Palombo D, Scarnò D, Zaniboni M, Del Fabbro M. Dental implants placed in severely atrophic jaws reconstructed with autogenous calvarium, bovine bone mineral, and collagen membranes: A 3- to 19-year retrospective follow-up study. Clin Oral Implants Res. 2018 Jul;29(7):725-740.

10. Esposito M, Grusovin MG, Kwan S, Worthington HV, Coulthard P. Interventions for replacing missing teeth: bone augmentation techniques for dental implant treatment. Cochrane Database Syst Rev. 2008 Jul 16;(3):CD003607.

11. Gleizal AM, Beziat JL. Maxillary and mandibular reconstruction using bicortical calvarial bone grafts: a retrospective study of 122 reconstructions in 73 patients. Plast Reconstr Surg. 2007 Feb;119(2):542-8

12. Sahoo N, Roy ID, Desai AP, Gupta V. Comparative evaluation of autogenous calvarial bone graft and alloplastic materials for secondary reconstruction of cranial defects. J Craniofac Surg. 2010 Jan;21(1):79-82

13. Jung RE, Zembic A, Pjetursson BE, Zwahlen M, Thoma DS. Systematic review of the survival rate and the incidence of biological, technical, and aesthetic complications of single crowns on implants reported in longitudinal studies with a mean follow-up of 5 years. Clin Oral Implants Res. 2012 Oct;23 Suppl 6:2-21.

14. Mertens C, Freier K, Engel M, Krisam J, Hoffmann J, Freudlsperger C. Reconstruction of the severely atrophic edentulous maxillae with calvarial bone grafts. Clin Oral Implants Res. 2017 Jun;28(6):749-756.

15. Pjetursson BE, Thoma D, Jung R, Zwahlen M, Zembic A. Systematic review of the survival and complication rates of implant-supported fixed dental prostheses (FDPs) after a mean observation period of at least 5 years. Clin Oral Implants Res. 2012 Oct;23 Suppl 6:22-38.

16. Putters TF, Schortinghuis J, Vissink A, Raghoebar GM. A prospective study on the morbidity resulting from calvarial bone harvesting for intraoral reconstruction. Int J Oral MaxillofacSurg. 2015 Apr;44(4):513-7.

17. Quiles JC, Souza FA, Bassi AP, Garcia IR Jr, França MT, Carvalho PS. Survival rate of osseointegrated implants in atrophic maxillae grafted with calvarial bone: a retrospective study. Int J Oral Maxillofac Surg. 2015 Feb;44(2):239-44.

18. Restoy-Lozano A, Dominguez-Mompell JL, Infante-Cossio P, Lara-Chao J, Lopez-Pizarro V. Calvarial Bone Grafting for Three-Dimensional Reconstruction of Severe Maxillary Defects: A Case Series. Int J Oral Maxillofac Implants. 2015 Jul-Aug;30(4):880-90.

19. Smolka W, Bosshardt DD, Mericske-Stern R, lizuka T. Reconstruction of the severely atrophic mandible using calvarial split bone grafts for implant-supported oral rehabilitation. Oral Surg Oral Med Oral Pathol Oral Radiol Endod. 2006 Jan;101(1):35-42.

20. Van der Meij EH, Blankestijn J, Berns RM, Bun RJ, Jovanovic A, Onland JM, Schoen J. The combined use of two endosteal implants and iliac crest onlay grafts in the severely atrophic mandible by a modified surgical approach. Int J Oral Maxillofac Surg. 2005 Mar;34(2):152-7.

21. Van Velzen FJ, Ofec R, Schulten EA, Ten Bruggenkate CM.10-year survival rate and the incidence of peri-implant disease of 374 titanium dental implants with a SLA surface: a prospective cohort study in 177 fully and partially edentulous patients. Clin Oral Implants Res. 2015 Oct;26(10):1121-8.

22. Von Arx T, Buser D. Horizontal ridge augmentation using autogenous block grafts and the guided bone regeneration technique with collagen membranes: a clinical study with 42 patients. Clin Oral Implants Res. 2006 Aug;17(4):359-66.

23. Cawood JI, Howell RA. A classification of the edentulous jaws. Int J Oral Maxillofac Surg. 1988 Aug;17(4):232-6.

24. Morrison A, Brady J. Mandibular reconstruction using nonvascularized autogenous bone grafting. Curr Opin Otolaryngol Head Neck Surg. 2010 Aug;18(4):227-31. 